\title{
E-Commerce: Expectations and Shortfalls
}

\author{
Angshuman Hazarika*
}

\section{Abstract}

The concept of E-commerce has existed since the inception of the internet, but it has acquired significance in the recent years. India being one of the fastest growing E-commerce markets in the world has no specific legislation to protect the interests of the buyers and sellers of goods and services over the electronic medium. The situation is further complicated by the fact that a typical transaction over the internet or phone needs the involvement of many service providers including a payment gateway, the main website, the bank or card verification website, the security certification website and the final service provider, which includes the shipping agent who delivers the goods. Separate laws are required to regulate the functioning of all these intermediaries. The paper examines the existing provisions available for the protection of the buyers and sellers who conduct transactions through the electronic medium. Further, the customer protection policies of four dominant Ecommerce websites in India being flipkart.com, irctc.co.in, makemytrip.com and groupon.co.in are evaluated. A few cases of consumer disputes arising over transactions conducted over the electronic medium are also discussed. Lastly, the paper analyses the measures which needs to be taken to provide protection to buyers and sellers on the internet.

Keywords: Consumer Protection, Consumer Redressal, ECommerce, Intermediaries, Internet

* Third Year, BA LLB, Rajiv Gandhi National University of Law, Punjab; angshuman7@ sify.com. 


\section{Introduction}

In recent times, the traditionally operated models of business have become obsolete and in many cases are not rendering enough revenue to the owners or shareholders of the company. A typical example of such a situation is the business of newspapers in the United States of America wherein many of the prominent newspapers have shut down or have shifted purely to the online medium. ${ }^{1} \mathrm{New}$ and innovative models and types of business need to be invented and operated. Presence of E-commerce in the market is fulfilling the need for innovativeness in the traditional business sectors. Businesses, both existing and new are trying to create an online identity and an E-commerce platform keeping in view the needs of the modern times. ${ }^{2}$

E-commerce is one of the subsets of e-business. ${ }^{3}$ It holds a similar meaning of traditional business wherein goods and services are exchanged for a particular amount of consideration. The only extra element it has is that the transaction here takes place through a digital mode of communication like the internet. Earlier, it was only the internet which was treated as a mode of transaction and communication for E-commerce. With the extensive growth of mobile communication and its related technologies like short messaging service, the scope of E-commerce has widened even more. E-commerce provides an opportunity for the sellers to reach the end consumer directly without the intervention of the middlemen. ${ }^{4}$

The success of each and every business depends upon the effectiveness and smoothness of operations and E-commerce is no

1 Suzanne M. Kirchhoff, The U.S. Newspaper Industry in Transition (Sept. 9, 2009), available at http://www.fas.org/sgp/crs/misc/R40700.pdf.

2 T.P. Rama Rao, E-commerce and Digital Divide: Impact on Consumers, available at http://www.iimahd.ernet.in/egov/documents/ecommerceand-digital-divide.pdf (last visited May 27, 2013).

3 Rajiv Shah, E-commerce, available at http://www.indiaitlaw.com/ ecomm.htm (last visited Mar. 14, 2012).

4 Richard Duncombe, Richard HEEKS et al., ECOMMERCE FOR SMALL ENTERPRISE DEVELOPMENT 204 (2006). 
exception. The presence of E-commerce in the market has brought out several effective changes in the methods of operating a business. The functional areas of business have improved with greater emphasis on cost cutting and consumer satisfaction.

The theory of Vasudhaiva Kutumbakam ${ }^{5}$ has started taking its shape in the era of E-commerce. Now the businesses are not just limited to the local proximity of one nation rather it has expanded to the global markets. Thus it fulfills the growth and expansion demands of a business by helping them in identifying and evaluating new markets all across the globe. Further, for capturing of new markets and their maintenance, businesses have to come up with new differentiators, value addition points etc. The large number of competitors in virtually every sector makes E-commerce a highly challenging venture.

New models of business demands different organisational frameworks. E-commerce demands an organisational framework which caters to its new marketing needs. The other points of considerations in it are the negotiation skills, electronic money transfer and taxation, new regulatory framework etc. ${ }^{6}$ This mode of business enables businesses to save time on product design and devise products according to the individual customer specification, track sales and get instant feedback from the customers.

\section{Growth of E-commerce}

The integral force behind the growth of E-commerce business is computer and information technology networks. Both consumers and businesses prefer E-commerce because of its inherent advantages. For consumers, it provides a cost effective mode to compare multiple options of the same product of service and for businesses it enables them to showcase their unique selling points (USPs) to every consumer. It is stated that E-commerce in India hit $\$ 10$ billion by the end of last year (2012) and continues to grow at a

${ }^{5}$ Shah, supra note 3.

${ }^{6} \mathrm{Id}$. 
fast pace.7Every E-commerce transaction depends on a number of intermediaries and it is much more than a click of a button to purchase a product. Further any regulatory medium for Ecommerce transactions would also need to include the intermediaries involved in the delivery of the product.

\section{Modes of Conducting Business through E-commerce}

E-commerce businesses have been segregated on the basis of different participants like business enterprise, customer and government. ${ }^{8}$ Its classification is as similar as the traditional business classification which is also based upon the number of members or owners or shareholders or participants like company, partnership and sole proprietorship. Although there are different models for classification of E-commerce, for simplicity, one of the models which is most suitable to the Indian scenario is considered here. ${ }^{9}$ Business through the medium of E-commerce has been classified on the basis of different participants as follows: ${ }^{10}$

a) Business to Business Transactions (B2B):

E-commerce transactions of this nature take place between various business entities like industries, companies, wholesalers and retailers. Business in this medium basically takes place through an intermediary website which links the two businesses. Prominent market leaders in this segment are www.alibaba.com and www.indiamart.com.

b) Business to Consumer Transactions (B2C):

7 The Screen Revolution, THE ECONOMIST, Mar. 16, 2013, available at http:// www.economist.com/news/business/21573551-meet-nextgeneration-indian-technology-firmsand-obstacles-they-face-screen.

${ }^{8}$ Know the Different Types of E-Commerce (Mar. 6, 2011), available at http://www.roseindia.net/tutorial/ecommerce/type-ofEcommerce.html. 9 Sarbapriya Ray, Emerging Trend of E-Commerce in India: Some Crucial Issues Prospects and Challenges, 2(5) COMPUTER ENGINEERING AND INTELLIGENT SYSTEMS 19, 20 (2011).

10 Ayad Ahmad Shariff K, Factors Affecting the Growth of E-Business in India and Importance of SMEs, INTERNATIONAL CONFERENCE ON TECHNOLOGY AND BUSINESS MANAGEMENT (Mar. 28-30, 2011). 
This is the sector which is most widely publicized and has a significant impact on the end consumer. Transactions in this sector take place between the business entities and the end consumer. Certain E-commerce sites in this segment also act as intermediaries for other businesses. As such sites in this segment can be classified into two main groups. Firstly, websites which provide goods and services directly to customers, example, www.flipkart.com, www.myntra.com and secondly websites which act as intermediaries between businesses and consumers, example, www.ebay.in and www.tradus.com.

\section{Legal Framework Relating to E-Commerce}

With the increasing importance and value of E-commerce in India and all across the globe, the different stakeholders are continuously identifying and evaluating the nuances of legal framework relating to it. The involvement of different service providers in the transactions of E-commerce, which includes a payment gateway, the main website, the bank or card verification website, the security certification website and the final service provider which can also include the shipping agent has made the E-commerce business more complicated. Therefore the need for regulating it has increased. In India, till date there are no specific legislations or guidelines protecting the buyers and sellers of goods and services over the electronic medium. ${ }^{11}$ However, several laws acting in conjunction are trying to regulate the business transactions of Ecommerce. They are as follows:

- Indian Contract Act 1872

- Consumer Protection Act 1986

- Information Technology Act 2000 (As amended in 2008)

- Indian Copyright Act 1957

Like any other type of business, E-commerce business also operates on the basis of contracts. It is therefore regulated by the Indian

${ }^{11}$ Akshat Razdan, The Future of E-Commerce in India, LAW WIRE, available at http://www.lawinfowire.com/articleinfo/future-ecommerce-india (last visited Apr. 4, 2013). 
Contract Act 1872. Any valid and legal E-contracts can be formed, performed, and enforced as parties replace paper documents with electronic equivalents. ${ }^{12}$ The contracts are entered into between the service providers or sellers and buyers.

Earlier, there was no specific law to regulate the intermediaries such as verification service providers and shipping service providers to ensure that the product or service is actually delivered. However, the government has recently notified the Information Technology (Intermediaries Guidelines) Rules 2011.13 The actual scope of the protection provided under these regulations would only be known after judicial interpretation of the provisions. However, now it has been clarified that even foreign intermediaries entrusted to provide service can be sued in India. ${ }^{14}$

The payment gateways which hold a very important position as the primary processor of the payments for the merchants were brought into the legal framework after promulgation of the Payment and Settlement Systems Act 2007 (PSS Act 2007). The PSS Act 2007 as well as the Payment and Settlement System Regulations 2008 framed under the Act came into effect from August 12 2008.15 Further, the Reserve Bank of India issued additional guidelines instructing all such gateways and payment processors to register under the said Act.

The validity of the transactions of E-commerce is established under the Information Technology Act 2000 (IT Act 2000). It defines the reasonable mode of acceptance of the offer. IT Act 2000 also

12 Aashit Shah \& Praveen Nagree, Legal Issues in E-Commerce (Mar. 14, 2012), available at http://www.nishithdesai.com/Research-Papers/ Legal_issues_ecom.pdf.

13 PTLB, Information Technology (Intermediaries Guidelines) Rules 2011 of India, available at http://bsu.bih.nic.in/(S(qpg2x155q2hkemisojswvv45))/ static/downloads/itact/it-intermediaries-guidelines-rules-2011.pdf (last visited Mar. 23, 2013).

14 Id.

15 Reserve Bank of India, Overview of Payment Systems in India, available at http://www.rbi.org.in/scripts/Payment Systems_UM.aspx (last visited Mar. 26, 2013). 
governs the revocation of offer and acceptance. ${ }^{16}$ However, specific provisions that regulate E-commerce transactions conducted over the internet, mobile phones etc. are absent. With several cross border transactions also being conducted over the internet, specific law protecting the Indian customers and Indian businesses are required and Indian laws are gravely inadequate on this issue.

In a bid to ensure security, the government has made digital signatures compulsory in several E-commerce transactions mainly in the government to government $(\mathrm{G} 2 \mathrm{G})$ or government to business (G2B) framework with a view to ensuring the identity of the transacting parties. E-commerce transactions on these modes require digital signatures as a compulsory ingredient. They are used for the authentication of the electronic contracts. These are regulated by the IT Act 2000 which provides the framework for digital signatures, their issue and verification. The Act thus tries to ensure that the trust between both the parties is maintained through verification of identities and help prevent cyber crimes and ensure cyber security practices. ${ }^{17}$

E-commerce and intellectual property rights are also very much related to each other. There are many instances wherein the intellectual property rights of a party are violated in the internet through an E-commerce website. These cases are regulated by the Indian Copyright Act 1957, Trademarks Act 1999 and also by several international tribunals through agreements and conventions. A famous case related to E-commerce and intellectual property rights was the case of oktatabyebye.com and Tata Industries, one of India's largest business conglomerates. The case which was decided by the WIPO Arbitration and Mediation Centre $^{18}$ related to the violation of the intellectual property rights of

16 Vikas Asawat, Information Technology (Amendment) Act, 2008: A New Vision through a New Change, (Mar. 16, 2012), available at http:/ / ssrn.com/abstract=1680152.

17 Dr.Shuchi Singhal, Digital Signatures: Bringing a Paradigm Shift in EBanking, 5(1) PACIFIC BusINESS REVIEW INTERNATIONAL61, 62 (2012).

18 Tata Sons Ltd. v. mmt admin / Oktatabyebye.com, Case No. D20090646, (Aug. 11, 2009), available at http://www.wipo.int/amc/en/ domains/decisions/html/2009/d2009-0646.html. 
the TATA group through the use of the 'oktatabyebye' phrase as a domain name by the respondents. The arbitration panel ultimately decided in favour of Tata group and handed them the domain name. This case also reveals the glaring absence of a domestic authority controlling domain names which are an integral part of E-commerce.

In the light of the above discussion, it is to be said that the present laws in respect of the regulation of E-commerce and its related operations are not satisfactorily serving the purpose. Proliferation of laws is creating a chaos in the smooth operations of the Ecommerce activities. Further, the present laws are silent on aspects of E-commerce such as payment mechanisms and delivery mechanisms and the present standard practices which have been developed by the industry. The Reserve Bank of India however has tried to strengthen the electronic payment mechanism through various orders, but such orders can only act as a stop-gap arrangement. ${ }^{19}$ The most important order in this regard was the implementation of second factor authentication in all Indian Payment Gateways. Commonly identified as Verified by Visa or MasterCard Secure Code, this had made card transactions on the internet relatively more secure.

To understand the real scenario of E-commerce in India, the authors have undertaken the case studies of some of India's largest E-commerce websites spread over a variety of sectors with particular reference to their various customer service and payment mechanisms. The article also analyses the problems with customer service and payment mechanisms.

\section{Scandals that Have Plagued E-Commerce}

E-commerce has been under regular spotlight mainly due to numerous scams that have arisen over a period of time. The most infamous of them include the following:

a) The Speak Asia Online Survey Fraud

${ }^{19}$ Bienu Vaghela, RBI Secures online credit card transactions, BUSINESS STANDARD, http://www.business-standard.com/india/storypage.php? autono=366362, (last visited Mar. 18, 2012). 
The Speak Asia Online Survey Fraud is probably the largest Ecommerce fraud in India pertaining to multi level marketing or MLM. ${ }^{20}$ The Economic Offences Wing has estimated that the fraud amounts to Rs. 2400 crore. ${ }^{21}$ The fraud could reach such levels owing to the availability of online medium for conducting the transactions. The modus operandi for the fraud involved the filling of online surveys to earn virtual points which could then be redeemed for money. However, for joining the scheme, every new entrant had to pay a fixed sum of money which he never received back. The money trail could not be traced in certain cases due to the fact that the parent company was registered in Singapore and a large sum of money had already been diverted there. At present the case is still under investigation with the Bombay High Court advising the police to file the charge sheet at the earliest. ${ }^{22}$

b) The Timtara Online Scam

Timtara.com was a 'business to consumer' E-commerce website which specialised mainly in electronic goods. The website became popular due to the large discounts provided on the products. However, the complaints of non delivery started to pour in about a year of the launch of the website. ${ }^{23}$ Customers complained of non delivery of products even after a year of payment. Further, allegations were raised regarding the customer service mechanism of the company wherein they had changed their office allegedly just to escape the wrath of the consumers. With mounting pressure,

${ }^{20}$ Yashpal Singh Bist, Charu Agarwal et al., Online Business Frauds: A Case Study of an Online Fraud Survey Company, 2(6) INTERNATIONAL JOURNAL OF MODERN ENGINEERING RESEARCH 4398, 4399 (2012).

${ }^{21}$ Khusboo Narayan \& Sangeeta Singh, Speak Asia Biggest Multi-Level Marketing Fraud, Says EOW, LIVE MINT, (Nov. 15, 2011), available at http:/ / www.livemint.com/Politics/tb55efFaUWGioaxzqQJ1EN/SpeakAsia-biggest-multilevel-marketing-fraud-says-EOW.html.

22 Press Trust of India, Speak Asia Scam: HC Slams Police for Clubbing Cases, THE FINANCIAL EXPRESS, (Jan. 9, 2013), available at http:/ / www.financialexpress.com/news/speak-asia-scam-hc-slamspolice-for-clubbing-cases/1056934.

${ }^{23}$ Dwaipayan Ghosh, Fraud Charge on Online Store, THE TIMES OF INDIA, (Mar. 31, 2013), available at http://articles.timesofindia.indiatimes.com/ 2013-03-31/delhi/ 38162706_1_home-appliances-shopping-portal-philips. 
the police recently arrested the directors of the company and investigations are underway regarding the mode of their functioning. New complaints continue to flow in everyday and the amount collected from customers allegedly exceeds Rs. 12 lakh. ${ }^{24 K e e p i n g ~ i n ~ v i e w ~ t h i s ~ s c e n a r i o ~ o f ~ n u m e r o u s ~ s c a n d a l s, ~ a ~ c a s e ~}$ study was undertaken to look into the payment mechanisms and the grievance redressal mechanism of some of the prominent players in the E-commerce sector. The following paragraphs examine those areas where regulations are required to protect the interests of the consumer.

\section{Indian Railway Catering and Tourism Corporation Limited}

Indian Railway Catering and Tourism Corporation Ltd (IRCTC) is undoubtedly the largest E-commerce site in India and is India's answer to private capitalist ventures. ${ }^{25}$ IRCTC was set up as a subsidiary of the Indian Railways for the exclusive purpose of providing catering facilities and ticketing services for the Indian Railways. However, of late it has expanded its wings and now covers sectors such as flights and hotel bookings. The flagship website www.irctc.co.in was established in 2002 and has revolutionised the online travel booking business in India. IRCTC operates both in the business to business and business to consumer segment. According to the statistics released by IRCTC, it has more than 4-4.5 lakh bookings per day. In 2010-11, IRCTC sold tickets worth more than Rs. 8000 crore. It claims to handle more than 8

\footnotetext{
${ }^{24}$ Bureau, Timtara Founder's Arrest Raises Concerns over Protection to Online Shoppers, THE HINDU BUSINESS LINE, (Apr. 1, 2013), available at http://www.thehindubusinessline.com/industry-and-economy/infotech/timtara-founders-arrest-raises-concerns-over-protection-to-onlineshoppers/article4570389.ece.

${ }^{25}$ Anirban Chowdhury, IRCTC Becomes the Largest Contributor to ECommerce, BUSINESS STANDARD, (Apr. 4, 2009), available at http://www.business-standard.com/article/technology/irctc-becomesthe-largest-contributor-to-e-commerce-109040400075_1.html.
} 
lakh parallel transactions thereby speaking volumes about the importance and the size of their business. ${ }^{26}$

The site provides the only link for purchasing Indian railway tickets online and even other agent sites (B2B) have to link them to IRCTC to provide online booking facilities for customers. IRCTC provides a large option for consumers for payment of buying tickets online. The payment options include internet banking, credit cards, cash cards and credit card equated monthly installments (EMI). The total number of payment options exceeds twenty and includes all major credit cards. IRCTC however is one of the few remaining E-commerce sites which levies transaction charges from customers. The transaction charges vary from bank to bank and are normally around $1.8 \%$ in case of debit cards and credit cards and Rs. 10 in case of internet banking payments. IRCTC also charges an extra amount from the consumers as service charge. The service charge varies from Rs. 10 to Rs. 60 for the class of ticket purchased. IRCTC also provides an EMI facility for credit card holders of certain banks through which the amount to be paid through installments in 3 or 6 months depending on a case to case basis.

\section{Charges and Refund Policy of Indian Railway Catering and Tourism Corporation Limited}

Tickets purchased from the IRCTC website are normally of two types- a) I-ticket and b) e-tickets. I-tickets are paper tickets delivered at the door step of the customer, while e-tickets are electronic tickets which the consumer can print at his home immediately after booking the ticket. The difference between the cancellation and refund of both the tickets is as that I-tickets need to be cancelled at a railway reservation counter while e-tickets can

26 Viraj Desai \& Harsimran Julka, We Are Sensitive to User's Pain from Congestion on IRCTC Website: Rakesh Kumar Tandon, THE ECONOMIC TIMES, (Feb. 23, 2012), available at http:/ / articles.economictimes.indiatimes.com/ 2012-02-23/news/31091228_1_irctc-website-indian-railway-cateringbookings. 
be cancelled online. The basic policies regarding cancellation of IRCTC tickets are as follows: ${ }^{27}$

i) A flat cancellation charge is levied by IRCTC ranging from Rs. 20 to Rs. 70 depending on the class of the ticket. For waitlisted tickets a lower amount called 'clerkage amount' is levied.

ii) The amount to be refunded depends on the time which is left for the departure of the train. The amount to be refunded is shown to the customer after he has made the cancellation request. 28

iii) The refund for both I-ticket and e-ticket cancellations are made back to the account from which the ticket was booked. ${ }^{29}$

iv) The IRCTC service charges and the transaction charges are not refunded. 30

v) Part cancellation of tickets is allowed. ${ }^{31}$

In case there is a failed transaction in which a customer pays the money, but no ticket is issued, IRCTC states that it seeks to reconcile such transactions and the amount is refunded as soon as the information is received from the railways. IRCTC states on its website that the actual time for the receipt of refund by a consumer extends from 3 days to 14 days and it also provides a chart comparing the refund times taken by various banks. ${ }^{32}$

27 Indian Railways Passenger Reservation Enquiry, Revised Refund Rules, available at http://www.indianrail.gov.in/refund_Rules.html (last visited Aug. 11, 2013); See also Indian Railways Passenger Reservation Enquiry, Reservation Rules, available at http://www.indianrail.gov.in/ reservation_Rules.html (last visited Aug. 11, 2013)

$28 I d$.

${ }^{29} I d$.

30 Indian Railway Catering and Tourism Corporation Limited, Refund Rules, available at https://www.irctc.co.in/beta_htmls/refundrules.html (last visited July 6, 2013).

$31 \mathrm{Id}$.

$32 \mathrm{Id}$. 


\section{Customer Care and Support}

IRCTC provides a 24 hour call centre facility through an all India number which is chargeable. It also lists its fax number, office address and customer care e-mail address under the 'contact us' heading on its website. ${ }^{33}$ The link also contains a separate contact number for Chennai and separate e-mail ids for different requests such as cancellations.

\section{Service Shortfalls of Indian Railway Catering and Tourism Corporation Limited}

IRCTC enjoys a virtual monopoly on the Indian Railway booking scene as it is the only medium through which online tickets for the Indian railways can be booked. Hence, the consumer has no option but to use the website or to book tickets using any other travel website using IRCTC as the intermediate medium. IRCTC thus has the advantage of controlling the entire market and hence needs to make policy changes with care.

In terms of consumer friendliness, IRCTC can consider making the following modifications:

i) The transaction charge of Rs. 10 or $1.8 \%$ of the ticket fare which is charged from the consumer for every ticket booked by the payment gateway is an old practice and is now not charged by any large E-commerce site and the practice should be discontinued as the consumer gets no benefit from this service.

ii) IRCTC makes no provision for refund of the service charges or the bank transaction charges even when the ticket is cancelled. Even for failed transactions, they are not refunded.

iii) The customer service number is not toll free and consumers have to pay for their calls.

iv) A proper grievance redressal mechanism for resolving the complaints is absent.

33 Indian Railway Catering and Tourism Corporation Limited, available at https://www.irctc.co.in/(last visited Aug. 11, 2013). 
IRCTC needs to take additional measures to improve its consumer service considering the large volume of transactions it handles and also due to the fact that it controls a monopoly business.

\section{Groupon}

Groupon India is one of the Indian sites which has come up in recent times to provide customers (operates in $\mathrm{B} 2 \mathrm{C}$ and $\mathrm{C} 2 \mathrm{~B}$ segments) with offers in deals through the online medium. Groupon.com ${ }^{34}$ in the United States provided huge discounts to consumers if they referred the deal to their friends and they also purchased the same. These websites work on the principle of acquiring a scheme from particular retailer on a product by promising them advertisement and access to a large consumer base who will be attracted to their brand and try it on the basis of the deal. This concept works well on the premise that the new customers would come, thus expanding the customer base of the store. What really happens is the customers purchasing the coupon are doing so because of the price, the next time they want to buy a product they will go back to the deal site and buy another deal this time of a different store. A Rice University study found that only about 1 in 5 daily deal users become repeat customers. ${ }^{35}$

\section{Payment Facilities for Consumers}

Groupon provides a large number of payment options for consumers which include internet banking, credit card, debit card, and cash on delivery and cash cards. A new payment facility available on this site is payment by phone, where a consumer can pay by using the interactive voice response (IVR) facility and make the payments through a credit card over phone thus minimizing the risk of online fraud. Groupon states in its 'frequently asked

\footnotetext{
${ }^{34}$ Groupon official website, available at http://www.groupon.co.in/ (last visited Aug. 11, 2013).

35 Josh Catone, Why Groupon Must Change Its Business Model for Long-Term Success (Oct.26, 2011), available at http://mashable.com/2011/ 10/ 26/ groupon-success-doubt/.
} 
questions' page that its payment gateways are highly reliable and that they use the 'best in class security'. ${ }^{36}$

\section{Charges and Refund Policies of Groupon}

Groupon on its website states that it provides its customers with a resolution of problems within 7 days of the submission of the grievance. It also provides a toll free contact number for its customers. ${ }^{37}$

\section{Service Shortfalls of Groupon}

Groupon.co.in is one of the new entrants to the E-commerce scenario and since the day of its inception has been a part of the ongoing competition between the deal sites like timesdeal.com, fashionandyou.com, dealsandyou.com. Hence, to carve a unique identity for itself, it has to provide service of the highest levels.

Groupon needs to look into the following areas for greater consumer friendliness:

i) The refund procedure should be clearly specified along with the conditions for refund.

ii) A dedicated complaint redressal system should be put in place to handle consumer grievance.

\section{Flipkart}

Flipkart.com is an online Indian retailer which is often called the Amazon of India. ${ }^{38}$ It was started in 2007as a website selling books online at rates cheaper than retailers. However, it later decide to expand and in 2010 started selling compact discs, computers, mobiles, home appliances, kitchen appliances online in addition to books. It is arguably India's most popular online retailer and is credited with changing the face of India's online retail business

\footnotetext{
$36 \mathrm{Id}$.

37 Groupon FAQ's, available at http:/ / www.groupon.co.in/faq (last visited Apr. 22, 2013).

38 Rohin Dharmakumar, Can Flipkart Deliver? FORBES INDIA, (July 6, 2012), available at http://forbesindia.com/article /boardroom /can-flipkartdeliver/33240/0.
} 
through its aggressive advertising campaign over print as well as digital media. In the financial year 2011-12, Flipkart had sales exceeding Rs. 500crore and the business are growing at a break neck speed. The scale of business of the site can be seen from the fact that it ships more than 17000 items daily and claims to have 17 orders every minute. ${ }^{39}$

\section{Business Area of Flipkart}

Flipkart.com deals with the sale of electronics, mobiles, home appliances, kitchen appliances, books etc. online. It primarily sold product directly to the consumers but now has also diversified itself into the commercial sector and allows sellers to sell their products through the website. It started a service called 'flyte' by which enabled customers to download music legally for a fee of around Rs. 6 per song. This was started to promote authorised downloads of music in India where the business of the Indian music industry has been severely hit due to illegal downloads. However, the service was shut down in June this year due to piracy issues. ${ }^{40}$

\section{Payment Facilities for Customers}

Flipkart.com provides a wide range of payment options for its customers like internet banking, credit cards, debit cards and cash cards. Like IRCTC it also provides an optional equated monthly installment facility for credit card holders of certain banks. Flipkart also provides the facility of cash on delivery for customers of certain cities and was a pioneer of this form of payment in India.

\section{Charges and Refund Policies of Flipkart}

Flipkart.com has a '30 day replacement guarantee' on all products sold through the website except for music downloads. Flipkart

39 Nandana Das, Excl: Flipkart Hits Rs 100cr Monthly Sales Mark, Now Serving 17 Orders per Minute (July 3, 2012), available at http:/ / techcircle.vccircle.com/2012/07/03/excl-flipkart-hits-rs-100crmonthly-sales-mark-now-serving-seven-orders-per-minute/.

${ }^{40}$ Flipkart's Flyte Fails to Fly Against the Piracy Wind, to Shut Down, IBNLIVE, (May 30, 2013), available at http://ibnlive.in.com/news/flipkarts-flytefails-to-fly-againt-the-piracy-wind-to-shut-down/394883-11.html. 
claims that it will replace all products on which complaints arise within the 30 day period after sale. All Flipkart products which are shipped are insured and the consumer can ask for a replacement in case of any damage in transit. Further, Flipkart provides the customers with an option to cancel their orders anytime before shipment in exchange for a full refund. Flipkart.com provides a dedicated 24 hours toll free customer support number through which its customers can contact for any queries or complaints. Further the website provides an option to contact through e-mail or through its website.

\section{Service Shortfalls of Flipkart}

Flipkart is one of the most consumer friendly websites in terms of consumer protection policies. The 30 day replacement guarantee is the first of its kind in India and it is hoped that it would be the business standard in future. However, Flipkartrequires a dedicated complaint redressal mechanism and also can establish offices for direct contact with customers.

\section{MakeMyTrip}

MakeMyTrip is one of India's largest private online travel websites and holds a large share of the domestic flight bookings in India. In fact it is thought that Makemytrip.comhas a market share of around $30 \%$ among the online travel agencies. ${ }^{41}$ Makemytrip.com is listed on the US Stock Exchange. It has specialised websites for United States, Canada, United Arab Emirates and Singapore, apart from India. MakeMyTrip provides facilities like flight, train, hotel and holiday bookings through the online medium and also through branch offices situated all over India. The site is regarded as the pioneer of online booking of tickets in India and is regularly visited by new customers.

\footnotetext{
${ }^{41}$ Ruchika Chitravanshi, Are Online Travel Companies Gouging Customers? BUSINESS STANDARD, (Apr. 25, 2012), available at http://www.businessstandard.com/article/companies/are-online-travel-companies-gougingcustomers-112042500036_1.html.
} 


\section{Payment Facilities for Customers}

MakeMytrip provides payment facilities through internet banking, credit cards, debit cards and cash cards. Further it also provides the facility of payment over the phone. However, an important feature of this site is the facility of payment through mobile applications.

\section{Charges and Refund Policies of MakeMyTrip}

MakeMyTrip takes an additional charge in every rail ticket booking, flight booking or hotel booking. However, this charge is frequently waived for certain bookings. For railway bookings, MakeMyTrip charges an additional Rs. 10 to 20 above the IRCTC ticket charges depending on the class of booking which is not refundable even on cancellation. For flight cancellations, MakeMyTrip charges Rs.250 for a domestic flight and Rs. 500/- for an international flight. MakeMyTrip also levies a transaction charge from its customers who purchase air tickets online. The transaction charge ranges from Rs. 125 onwards. A recent Supreme Court Judgment in the case of T.G.N.Kumar v. A.E.R.A. and Ors. ${ }^{42}$ had strictly prohibited the imposition of any transaction charge on the ticket. However, the practice continues unheeded among almost all the online booking websites. There are also additional charges payable in case of hotel booking cancellations or rescheduling over and above the hotel charges. MakeMyTrip provides a 24 hour toll free customer care number which can be accessed throughout India. Further it provides support through email as well as through the different MakeMyTrip offices that are located throughout India.

\section{Service Shortfalls of MakeMyTrip}

Makemytrip.com needs to look into its customer service policies to regain the trust of the customers. Further, MakeMyTrip can also start a dedicated consumer disputes redressal mechanism so that unresolved complaints can be solved by the highest authorities.

Further, Makemytrip.com needs to look into the excess charges which have to be borne by the customers while they cancel tickets

42 T.G.N. Kumar v. A.E.R.A. and Ors., Civil Appeal No. 8771 of 2012, Order dated 23.01.2013. 
on the website. They should adopt a more consumer friendly policy in line with certain other competing websites which no longer charge an additional cancellation charges.Makemytrip.com needs to evaluate its refund policies and put in a transparent mechanism in the light of several complaints which have been raised on the issue.

\section{Inferences that can be Drawn from the above Case Studies}

The main issues that have been identified from the case studies can be stated as follows:

a) Lack of regulation regarding payment mechanisms

There is an absolute lack of regulations regarding the mode of payments which needs to be provided by any E-commerce website and the transaction charges which they can impose. It is seen that numerous travel websites impose additional charges on the payment made by the customers. The websites state that it is an industry standard practice. This makes the matter even more complicated owing to issues of anti competitive practices.

Further, there are no standard Reserve Bank of India guidelines available especially for issues of refund transactions in the case of credit card and debit card payments. The standard guidelines available for point of sale (PoS) transactions may not apply to all Ecommerce transactions due to the involvement of multiple parties in these cases instead of two parties in a normal PoS transaction.

b) Need for Standards for Consumer Grievance Redressal

There should be standards prescribed by law regarding the customer service requirements to be fulfilled by an E-commerce venture. Providing a compulsory physical office and mandatory 24 hour call centre are some of the steps which should be undertaken. Further, the consumer courts should be made aware of the issue of E-commerce transactions and the special steps to be followed in such cases. Timelines should be prescribed for refunding the amount back to the customer's account in case of failed transactions or order cancellations. These guidelines should be applicable to the E-commerce merchants as well as the banks and payment gateways. 


\section{Conclusion}

E-commerce in India has certainly come a long way from the days of bazee.com which started as the first large online retail website. At present with the increase in number of internet user, Ecommerce is scheduled to grow further. The increasing trend of internet banking and credit or debit cards along with the rise in the number of educated and computer literate persons will further aid this growth. The need of the hour is a legislation which covers all the aspects of E-commerce ranging from the payment mechanism and maintaining minimum standards in the delivery of services. Such a legislation will help to curb the growth of websites which rise within a few days and then stop functioning in the absence of adequate funds for sustenance. As all business through Ecommerce sites is made through the internet without any direct physical interaction, the main basis of transaction is the trust of the customers which should be retained at any cost. A legislation in this field will discourage the criminals who have used the internet as a source for making quick money. This will also act a protection for the genuine E-commerce websites and help in the further growth of business. There is also a need for the establishment of an authority in the consumer court to look into the complaints arising out of E-commerce transactions. Such an authority should have experts in areas such as payment security. This will encourage speedy redressal of disputes and promote E-commerce transactions. Last but not the least, it is the E-commerce websites which need to take steps to ensure that customers are satisfied by their service, since word of mouth advertisement can act as the biggest means of attracting new customers. E-commerce which is an emerging segment in the commercial arenas scheduled to grow and it is the responsibility of the existing players to ensure that growth is not hindered by their acts and policies. 